\title{
COMO SE FOSSE BUMERANGUE \\ Frente Negra Brasileira no circuito transatlântico*
}

\section{Petrônio Domingues}

In the glorious march of the Race people throughout the world we will undoubtedly meet one another some day! "Brazilians send congratulations". Chicago Defender, 7 ago. 1937, p. 24.

No dia 8 de dezembro de 1934, o jornal da imprensa afro-americana Chicago Defender publicou um artigo de Robert S. Abbott. Intitulado "Intelecto é o único caminho para a liberdade", o artigo fazia uma reflexão em torno das potencialidades da inteligência humana, a "força motora que opera a roda giratória da civilização". Em determinado momento, o jornalista relacionava esse tema com uma ação coletiva de seus "irmãos" do Brasil: a fundação da Frente Negra Brasileira (FNB). Segundo Abbott, os

* O autor agradece a Ruan Reis, bolsista de iniciação científica PIBIC/CNPq, a Kim D. Butler (Rutgers University) e aos pareceristas ad hoc da revista, por suas pertinentes observaçōes e sugestōes a uma versão anterior deste texto.

Artigo recebido em 04/06/2010

Aprovado em 09/10/2012

\section{'BLACK FRONT' MEETING PLACE}

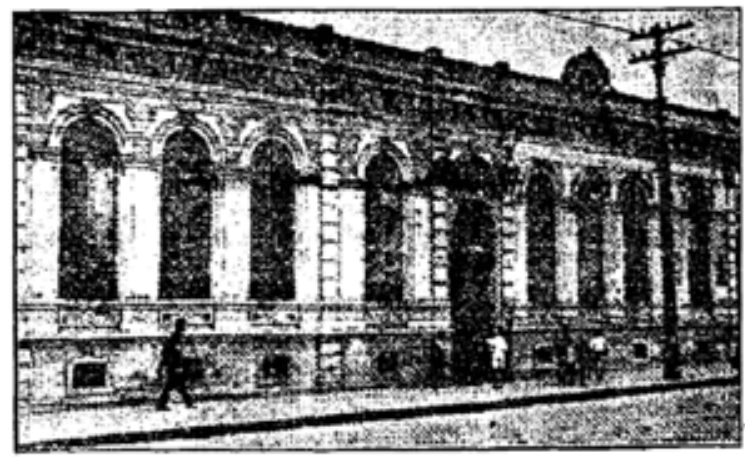

The offial building of the Fronte Negra in San Paulo, Braxil, where that great organization recently held an inter-sectional congress.

Fonte: The Chicago Defender, 9 nov. 1934, p. 3.

afro-brasileiros viram a sua liberdade ameaçada com a invasão de norte-americanos brancos em sua terra e, ao perceberem que os novos habitantes propagavam um clima de animosidade, na medida em que declaravam a "superioridade da sua casta racial sobre 
os amáveis negros", foram compelidos a dar uma resposta à altura, formando "uma organização conhecida como Frente Negra”, que se tornou "formidável, tanto numérica como politicamente", a ponto de o "espectro sinistro do preconceito ter sido praticamente extinto em setores como o exército, a marinha, a força policial municipal e estatal, as escolas de aviação e até as agremiações atléticas e sociais”.

Com apenas alguns anos de vida, a Frente Negra é hoje a mais poderosa organização em toda a América do Sul. Ela tem dinheiro, cérebros e força numérica para lutar e lutar duro contra qualquer medida que vise subtrair os vários direitos dos negros, qualquer movimento que vise sua limitação, subjugação ou isolamento. Esses homens têm lutado com seus cérebros e lutarão com suas mãos se forçados forem, e eles não temerão a morte. ${ }^{1}$

É interessante saber que a Frente Negra Brasileira foi objeto das atenções do mais importante jornal da imprensa afro-americana na década de 1930 , sendo qualificada como a "mais poderosa organização em toda América do Sul”. Em vista disso, a questão central deste artigo é discutir as narrativas, imagens e representações em torno da Frente Negra produzidas pelo Chicago Defender. E, a partir daí, procurar surpreender os diálogos no circuito afro-atlântico. Quando Robert Abbott retratou a Frente Negra como uma organização forte, guerreira e destemida, ele provavelmente carregou na tinta, mas essas imagens e representações não são destituídas de significado, na medida em que permitem entrever a importância que a organização dos afro-brasileiros alcançou na rede do transnacionalismo negro.

No final da década de 1990, Pierre Bourdieu e Loïc Wacquant publicaram um artigo que causou grande polêmica no mundo acadêmico. De modo bombástico, os sociólogos franceses denunciaram o imperialismo cultural norte-americano de impor para o mundo sua maneira de pensar, suas categorias analíticas e tradiçôes acadêmicas, inclusive no campo das relaçóes raciais. Arrogando-se como o centro de referência para qualquer comparação internacional, os Estados Unidos exportariam, de forma unilateral e insidiosa, agendas de pesquisa, abordagens, conceitos, experiências e narrativas intrínsecas ao seu sistema racial. Para os demais países, só restaria copiar os discursos, referenciais, paradigmas e projetos ditados pela maior potência do planeta. Mencionando o exemplo do Brasil, os sociólogos franceses acusavam os pesquisadores norte-americanos de, aqui, manipularem os líderes do movimento negro local a adotar as táticas, crenças e estratégias do Black Movement, o que, per si, era um grande perigo, pois, entre outros malefícios, forçava o aparecimento da "globalização da raça”, não a partir de uma convergência dos modos de "dominação etno-racial" nos diferentes países, mas antes por meio da quase "universalização do folk concept norte-americano de raça sob o efeito da exportação mundial das categorias eruditas americanas" (Bourdieu e Wacquant, 2002, p. 23). Vários autores refutaram os postulados de Bourdieu e Wacquant, argumentando que, entre os Estados Unidos e o Brasil, os intercâmbios no mundo das ideias se operam, não por imposições unilaterais e maquiavélicas, e sim por intermédio de trocas, empréstimos, apropriações e reelaborações mútuas (Hanchard, 2002; French, 2002; Sansone, 2002; Telles, 2002; Fry, 2005). Portanto, é um erro imaginar que, na arena das relações raciais, existe, de um lado, um país demiúrgico produtor $\mathrm{e}$ irradiador de posicionamentos, tendências e retóricas e, de outro, um país meramente receptor e reprodutor passivo dessas influências.

Autor de uma das críticas mais contundentes aos sociólogos franceses, Michael Hanchard evoca a armadilha de circunscrever a política e o pensamento "afro-norte-americanos" dentro das fronteiras geográficas dos Estados Unidos. Em vez de isolado, o movimento dos "afro-norte-americanos" conectava-se a uma rede mais ampla de luta por igualdade racial, a rede do "transnacionalismo negro, de que fazem parte tanto atores políticos afro-brasileiros como afro-norte-americanos dos Estados Unidos" (Hanchard, 2002, p. 74). Apesar de convincente, Hanchard - e os demais críticos de Bourdieu e Wacquant - limita-se a discutir o transnacionalismo negro por um viés mais coevo e pouco recua no tempo. Como se deram os diálogos entre o movimento dos afrodescendentes dos dois lados da linha do Equador antes da Segunda Guerra Mundial (1939-1945), um período anterior ao Movimento dos Direitos Civis? Longe de ter a pretensão de esgotar um assunto tão complexo em 
poucas laudas, o desiderato aqui é evidenciar que, na década de 1930, as lutas políticas, táticas de militância e metodologias discursivas em prol da igualdade racial de fato não respeitavam as fronteiras nacionais, circulando multilateralmente e viajando na rede de conexōes engendrada no Atlântico Negro. Como se fossem um bumerangue, ${ }^{2}$ informaçōes, ideários, sonhos, esperanças e experiências de ativistas e organizaçōes negras interagiam com idas e voltas, em movimentos contínuos em vias de mão dupla.

\section{Quando os “homens de cor" se mobilizam}

Analisar o Chicago Defender é relevante pela possibilidade de cotejar, entre outras coisas, como foram pensadas as questões relacionadas com raça, identidade, cultura e nação no circuito afro-atlântico. Porém, antes de discutir as imagens e representações veiculadas sobre a Frente Negra pelo órgão da imprensa afro-americana, faz-se necessário apresentar algumas notas atinentes à trajetória dessa agremiação. Em 3 de outubro de 1930, Getúlio Vargas liderou uma coalizão de forças civis e militares e, por meio de um golpe de Estado, chegou ao poder no Brasil. Instaurou-se uma conjuntura de disputas, embates e fortes acirramentos políticos. A opinião pública, os atores e os grupos políticos se dividiram, em linhas gerais, em duas frentes antagônicas: a da esquerda e a da direita. Todavia, tanto as agremiações de caráter popular quanto as organizaçōes das elites não previam em seus programas a defesa dos direitos da população negra. Cansado de ser preterido pelo sistema político tradicional e acumulando a experiência de décadas de vida associativa no pós-abolição, um grupo de "homens de cor" - como se dizia na época - empreendeu uma mobilização racial em São Paulo que redundou na criação da Frente Negra Brasileira (FNB), na noite de 16 de setembro de 1931. Quase um mês depois, em assembleia realizada no saláo das Classes Laboriosas, foi apresentado e aprovado o estatuto, documento no qual ficavam definidas as linhas mestras da organização:

Fica fundada nesta cidade de São Paulo, para se irradiar por todo o Brasil, a "frente negra brasileira”, união política e social da Gente Negra
Nacional, para afirmação dos direitos históricos da mesma, em virtude da sua atividade material e moral no passado e para reivindicação de seus direitos sociais e políticos, atuais, na Comunhão Brasileira (Diário Oficial do Estado de São Paulo, 4/11/1931, p. 12.).

A adesão da "população de cor" deu-se em escala crescente. Ano após ano o número de afiliados aumentava. No seu auge, a entidade contava com milhares de associados. No entanto, os números são contraditórios e pouco confiáveis. Michael Mitchell estimou em 6 mil sócios em São Paulo e 2 mil em Santos (1977, p. 131). Francisco Lucrécio - um remanescente frentenegrino - avaliou, décadas depois, que, se fosse para "fazer os cálculos, [ela] superaria os vinte mil filiados" (Lucrécio et al., 1998, p. 39). Florestan Fernandes contabilizou em 200 mil, sem contudo especificar se esse número era válido apenas para São Paulo (1978, p. 59). Em 1936, o jornal $A$ Voz da $R a c ̧ a$ anunciava que a entidade era formada por mais de "sessenta delegaçôes" (espécie de filiais) distribuídas no interior de São Paulo e em outros estados, ${ }^{3}$ como Rio de Janeiro, Minas Gerais, Espírito Santo, além de servir de fonte de inspiração para o soerguimento de organizaçōes homônimas em Pelotas (no Rio Grande do Sul), Salvador e Recife. ${ }^{4}$ No início, sua sede social foi instalada num modesto escritório, localizado no Palacete Santa Helena, na regiáo central de São Paulo. Porém, como o número de afiliados crescia e o movimento adquiria proporções cada vez maiores, a sede foi transferida para um casarão da rua Liberdade, 196 (onde atualmente funciona a Casa de Portugal), também na região central da capital paulista. A sede era ampla, imponente e bem estruturada. No seu interior havia salas da presidência, da secretaria, da tesouraria, das reunióes e dos diversos departamentos. Mantinha-se um salão de beleza, bar, local para jogos, gabinete dentário e um posto de alistamento eleitoral (Pinto, 1993). Contava-se ainda com espaço para o funcionamento de uma escola, de cursos profissionalizantes, de um grupo teatral, de um grupo musical, além de um salão para as realizaçôes das festas e cerimônias oficiais.

Sua organização político-administrativa era complexa e diversificada. Havia centralização do poder e predominava uma rigorosa estrutura hierárquica. Ao longo de seu percurso, a FNB possuiu dois presiden- 
tes. O primeiro foi Arlindo Veiga dos Santos, que ocupou o cargo até pedir afastamento, em junho de 1934. Com sua saída, assumiu a presidência Justiniano Costa, que até então exercia a função de tesoureiro da entidade. No que tange à origem social, a maior parte dos afiliados de base tinha uma origem humilde, sendo funcionários públicos, trabalhadores de cargos subalternos e de serviços braçais. Muitos eram subempregados ou simplesmente desempregados. Por sua vez, os cargos de direção da agremiação eram ocupados, geralmente, por negros em estado de mobilidade social, quando não inseridos nos estratos intermediários do sistema ocupacional da cidade.

No que se refere às questões político-ideológicas, a FNB caracterizou-se por preconizar um projeto nacionalista, de viés autoritário. Arlindo Veiga dos Santos, por exemplo, era refratário à democracia liberal e amiúde fazia apologia dos movimentos fascistas europeus em voga (Andrews, 1998, p. 238). Aos finais de semana, a agremiação promovia na sede central as famosas domingueiras, encontros nos quais lideranças e intelectuais (negros e brancos) ministravam palestras e transmitiam valores morais e ideais cívicos e políticos. A FNB forjou uma série de símbolos identitários (como bandeira, hino, carteira de associado), assim como criou a Milícia Frentenegrina. Tratava-se de um batalhão paramilitar, composto especialmente por jovens.

Nessa jornada de mobilização racial, as mulheres não perderam o bonde da história, assumindo diversas tarefas e protagonizando diferentes ações. A Cruzada Feminina reunia as negras tendo em vista a realização de trabalhos assistencialistas. Já outra comissão feminina, chamada Rosas Negras, animava festas, bailes e atividades artísticas. Para fomentar ou mesmo desenvolver os projetos específicos, a agremiação montou vários departamentos: o jurídico-social, o médico, o de imprensa, que era o responsável pela publicação do jornal $A V o z d a$ Raça; o de propaganda, o dramático, o musical, o esportivo e o de instrução (Domingues, 2005).

\section{Pelo prisma do Chicago Defender}

No dia 14 de outubro de 1933, o jornal Chicago Defender informava aos seus leitores, na primeira página, que os afro-brasileiros estavam dando uma resposta ao nefasto "preconceito de cor" importado dos Estados Unidos: "O esforço de certos imigrantes da parte Sul dos Estados Unidos em organizar uma Ku Klux Klan brasileira recebeu uma resposta do povo desta nação", quando se soube que "em São Paulo e na Bahia organizou-se uma sociedade conhecida como Frente Negra. Esta, apesar de ter apenas poucos meses de vida, já conta com mais de 50.000 membros". 5 Dois anos depois, o jornal noticiava - mais uma vez na primeira página - que no Brasil a Frente Negra, com seus "dez mil membros", promovera uma manifestação pelas "principais ruas do Rio de Janeiro". Essa organização, composta "exclusivamente por negros brasileiros", estava direcionando suas energias contra o solapamento dos "direitos civis e constitucionais". Nesse sentido, ela "tem tido eminente sucesso", combatendo as "forças do preconceito racial que por um tempo ameaçou minar o espírito tradicional de justiça e igualdade pelo qual o Brasil ficou conhecido" no concerto das naçōes. Graças à sua ação, tem-se derrubado as "barreiras que impedem o progresso social dos negros", de modo que "hoje não existem instituições de escala local ou nacional, de importância política ou social, na qual os negros não estejam representados". No final da matéria, o jornal reportava que "a mais poderosa organização em todo o Brasil" tinha realizado uma "grande convenção no Rio de Janeiro", ocasião na qual o "honorável" Robert S. Abbott, editor do Chicago Defender, foi homenageado. O "presidente" da convenção teria declarado:

A Frente Negra veio a lume pelo exemplo do grande editor norte-americano Robert S. Abbott. Foi ele quem transplantou para o nosso solo a filosofia militante de integração nacional de todos os elementos raciais. Foi ele quem levou adiante sobre o nosso continente os grandes princípios da nossa organização. Nós, portanto, em gratidão, paramos no meio das nossas deliberações para honrar o seu nome. ${ }^{6}$

De acordo com o Chicago Defender, foi Robert S. Abbott quem persuadiu os brasileiros a se organizarem contra a "invasão" do preconceito que 
gradualmente chegava ao país tropical, com a entrada de imigrantes brancos norte-americanos. "Agindo sob seu conselho, os brasileiros de pele negra fundaram a Frente Negra Brasileira, que tem tido sucesso na luta contra o preconceito". ${ }^{7}$ Mas quem era Robert Sengstacke Abbott? Ele fora, de fato, o mentor da FNB? Afro-americano de origem humilde, Abbott nasceu de pais ex-escravos na Geórgia, em 1868, e estudou no Instituto Hampton, na Virgínia, onde aprendeu o ofício de tipógrafo, e no Colégio de Direito em Kent, em Chicago. Depois de trabalhar na área do Direito por um curto período de tempo, fundou em 1905 o jornal Chicago Defender, na cidade de Chicago, tornando-se o seu editor (Ottley, 1955). O jornal fazia parte da imprensa negra norte-americana e, como argumenta Gunnar Myrdal, essa imprensa desempenhou uma importância "enorme" na formação da opinião da população afro-americana, para o funcionamento de suas instituições (como igrejas, escolas e agremiaçōes recreativas), para a visibilidade de suas lideranças e para a coordenação de suas açôes coletivas, enfim, a imprensa negra era um órgão educacional "muito poderoso" (Myrdal, 1944). Publicaçōes como The Baltimore Afro-American, New York Amsterdam News, Guardian, Negro World, Messenger, The Pittsburgh Courier, Norfolk Journal and Guide, The Crisis, entre outras, passavam de uma família para outra e, às vezes, eram lidas em voz alta em reuniōes informais. Eram, também, postos à disposição dos interessados nos salōes de barbeiros, nas lojas, nas igrejas, nas escolas, nas sociedades recreativas e nos salōes de bilhar. Seu conteúdo era transmitido verbalmente aos que não sabiam ler. Direta ou indiretamente, essa imprensa exercia influência sobre grande parcela da população afro-americana. ${ }^{8}$

Em 1920, várias publicações haviam atingido uma tiragem semanal de 100 mil exemplares e, dez anos mais tarde, algumas ediçōes alcançaram tiragem acima de 150 mil exemplares. Não obstante, foi o Chicago Defender quem mais adquiriu projeção no período. Em uma década, a publicação passou de um pequeno tabloide para o maior (e mais influente) jornal da imprensa afro-americana, com distribuição nacional e tiragens de cerca de $250 \mathrm{mil}$ exemplares. ${ }^{9}$ Realçando o discurso de orgulho racial e as notícias relacionadas com os "feitos" indi- viduais dos negros, suas páginas se tornaram uma tribuna aberta contra a segregação racial - o regime Jim Crown - nos Estados Unidos. Além de denunciar os ataques e linchamentos contra a população negra, o Chicago Defender instava os seus leitores do Sul do país que migrassem para os centros industriais em busca de trabalho ou para os estados do Norte, onde as oportunidades eram presumivelmente maiores e o preconceito racial menos nefasto. A notabilidade que o jornal alcançou nos Estados Unidos permitiu a Robert Abbott, seu editor, os recursos necessários para viajar pela América do Sul e satisfazer a sua vontade de conhecer uma experiência negra distinta daquela vivida pelos seus conterrâneos de cor.

Em 1923, ele desembarcou, junto com a esposa, no Brasil, onde fez turismo, participou de encontros sociais, proferiu palestras para estudantes, intelectuais, políticos, jornalistas e estabeleceu contatos amistosos com alguns negros. O editor do Chicago Defender completaria sua estada de três meses na América do Sul com uma viagem para a Argentina. Esse tour pela região teria causado fortes impressões em Abbott, de modo que, ao voltar ao seu país de origem, ele passou a acompanhar a política racial do Brasil (Hellwig, 1988) e, tempos depois, fomentou um intercâmbio com as lideranças do "movimento associativo dos homens de cor", por meio de correspondências e trocas entre o Chicago Defender e O Clarim da Alvorada, o mais importante jornal da imprensa negra brasileira na década de 1920 (Seigel, 2007, pp. 330-331). ${ }^{10}$ Sem dúvida, Abbott tornou-se um aliado dos afro-brasileiros, mas isso não permite afirmar que ele tenha sido o mentor, tampouco o responsável pelo "eminente sucesso" da FNB. Deve-se a Francisco Costa Santos a proposta de fundar uma agremiação dedicada à elevação moral, intelectual e social da "população de cor". No irromper de 1931, "Chico", como era mais conhecido, teria comentado e convencido Isaltino Veiga dos Santos a esposar a ideia. A partir de então, ambos os ativistas afro-paulistas passaram a liderar um pequeno, porém crescente movimento social que resultou na fundação da FNB. Portanto, a agremiação não foi obra de Abbott. Esta versão dos fatos foi inventada pelo Chicago Defender, pois era comum, em suas páginas, 
o "destemido militante editor" - cujo sonho era transformar a "América numa terra onde igualdade econômica, política e cultural fosse um fato e não uma teoria"11 - ser heroicizado, com seus "feitos" lembrados e relembrados, quando não mistificados.

De toda sorte, foi o jornal de Abbott que de maneira crescente abriu espaço, em sua edição semanal, para se reportar à emergência da FNB. Pesquisando no arquivo do Chicago Defender, foram localizadas 427 matérias, reportagens, notas ou mençôes ao Brasil na década de 1930. Só para o período de 1933 a 1937 foram encontradas 45 reportagens pautando a questão racial, das quais 29 se referiam à associação dos afro-brasileiros. Para obter as informaçōes, o Chicago Defender valia-se da Foreign Press Service, sua agência de notícias internacionais. Metz T. P. Lochard foi um dos jornalistas que, dos Estados Unidos, escreveu sobre o Brasil. O órgão da imprensa afro-americana valeu-se também de colaboradores no Brasil. Todavia, não é possível saber quem eram esses colaboradores, nem sua nacionalidade, pois as matérias e reportagens não eram assinadas - quando muito, elas estampavam o nome da agência (Defender Foreign Press Service) ou local (Rio de Janeiro, São Paulo ou Bahia) da fonte de notícias.

Em linhas gerais, o Chicago Defender difundiu discursos, imagens e representaçōes enaltecedores da FNB. Quando noticiou que esta promoveu um "congresso" em São Paulo, o jornal se reportou tanto às declaraçôes de apoio e solidariedade de "muitas organizaçōes" a ela, quanto destacou o comparecimento ao conclave de outras agremiaçóes afro-brasileiras - como o Grêmio Luiz Gama e a Legião Negra. Da mesma maneira, o periódico registrou a "declarada proposta da Frente Negra de coordenar os interesses de todos os negros brasileiros num esforço para unificar seus objetivos políticos e sociais". ${ }^{12}$ Por essa perspectiva, a FNB não seria uma simples agremiação afro-brasileira, porém a soberana, a mais ingente, arrojada e aglutinadora, a única organização dessa natureza capaz de reunir uma coalizão de forças vivas em prol de um projeto redentor.

Como vimos, a FNB era dividida internamente em departamentos - como jurídico, médico, dramático, artístico, musical, esportivo, educacional -, os quais animavam atividades diversificadas.
Entrementes, ela foi vista (e celebrada) pelo Chicago Defender menos como um espaço de sociabilidade, cultura e lazer e mais como um "notável" movimento reivindicativo. Em 13 de junho de 1936, o jornal relatava que os representantes da agremiação "têm se reunido com altos oficiais do governo pelos últimos dois meses", a fim de definir um programa capaz de garantir "uma segurança financeira para todos os negros e pessoas do grupo minoritário". ${ }^{13}$ Se comparada às suas congêneres, a FNB decerto reuniu uma sólida estrutura organizacional e administrativa, contudo sua força política foi superestimada pelo Chicago Defender. Ao abrir espaço para discutir a possibilidade de o governo brasileiro reconhecer o partido da agremiação, o periódico assinalava: "Muitos acham que tal reconhecimento trará, dentro de um período relativamente curto, ganhos para os membros dessa organização, em todas as questôes as quais tem se deparado". E não estaria fora de cogitação um negro ser "elevado, na esfera pública, a presidente da república". ${ }^{14}$ Será que esse negro seria oriundo da FNB? Em caso de resposta positiva, não era para menos. "De pequena e tímida associação", anunciava o órgão da imprensa afro-americana, "a Frente Negra passou para a mais formidável, militante e agressiva organização em toda a América do Sul". Ela teria se insurgido contra o problema da segregação e do tratamento injusto; estaria "abrindo as portas que foram fechadas", o que forçou as "instituiçōes nacionais" a admitirem todos, "sem considerar a cor". Em função disso, os principais partidos políticos passaram a querer "barganhar" com a organização, "que define agora o equilíbrio do poder". ${ }^{15}$

Para o Chicago Defender, a Frente Negra não era uma mera coadjuvante do sistema político-institucional brasileiro, mas antes a principal protagonista, cujo poder de negociação era de importância capital para o destino da nação. No final de 1936, a sucessão eleitoral de Getúlio Vargas foi objeto de especulações e confabulaçóes políticas. O clima de expectativas crescia. Quem seriam os candidatos a presidente? Um nome que veio à tona foi o de Oswaldo Aranha, o então embaixador do Brasil nos Estados Unidos e político de grande prestígio nas hostes governistas. Em 5 de dezembro de 1936, o Chicago Defender publicou uma reportagem na 
qual noticiava a visita de Aranha ao Brasil, para, entre outras coisas, reunir-se com Vargas e discutir o seu futuro político. Para o jornal da imprensa afro-americana, a falta de partidos políticos nacionais no Brasil complicava a campanha presidencial, pois o resultado final do pleito dependeria do alinhamento de "tão forte organizaçōes políticas como a Frente Negra". ${ }^{16}$ Por esse viés, a organização dos "homens de cor" do Brasil seria o verdadeiro fiel da balança nos destinos do país. Em artigo de 20 de março de 1937, o órgão da imprensa afro-americana voltava a exaltar o potencial político-eleitoral da FNB. Com a aproximação das eleiçôes nacionais, candidatos a altos cargos políticos estariam cortejando a "poderosa" Frente Negra na esperança de cooptar o "tremendo" poder de voto da organização para o lado dos seus partidos políticos favoritos.

O homem chave da "Frente Negra" até agora não se comprometeu com nenhum partido. Analistas políticos estão, entretanto, com a forte impressão de que a Frente Negra será o fiel da balança nas eleiçóes nacionais. $\mathrm{O}$ quadro de associados da Frente Negra, de acordo com fontes confráveis, conta com bem acima de 40 mil, com novos membros se alistando diariamente. Com essa sólida, inquebrável frente, essa organização representa hoje uma das mais poderosas forças a ser considerada no Brasil. ${ }^{17}$

Será que a FNB era uma potência política colossal no cenário nacional da década de 1930? George Reid Andrews argumenta que, fosse qual fosse o seu número, os membros da agremiação eram "aparentemente muito poucos para exercer qualquer impacto sobre a política eleitoral do Estado [de São Paulo]". Ora, se a sua expressão política era de fato limitada em âmbito estadual, o que se pode pensar em âmbito nacional? A FNB abriu um posto destinado ao alistamento eleitoral e realizou uma ampla campanha para inscrever seus membros como eleitores. Mas, em que pese esses esforços, a agremiação não elegeu "nenhum candidato durante seus sete anos de existência, e até experimentou alguma dificuldade em seu registro como partido político". As várias defecções - tanto de militantes, quanto de grupos $-\mathrm{e}$ as divisões internas foram outros fatores que contribuíram para debilitá-la. "Estas divisōes", afirma Andrews, "quando associadas ao tamanho pequeno do voto negro, impediam a Frente de algum dia atingir seu objetivo de se tornar uma força política importante" (Andrews, 1998, pp. 234239). Verifica-se, assim, como o Chicago Defender superdimensionou o poder de barganha da FNB. Não há dúvidas de que a agremiação alcançou um nível de organização respeitável, com suas lideranças se envolvendo em articulações, negociações e alianças diversas, no entanto isso não permite inferir que ela se constituiu no "fiel da balança" do sistema político-institucional brasileiro.

Seja como for, o Chicago Defender continuou produzindo um discurso de louvação da FNB em suas páginas. Desta feita, pelas presumíveis vitórias obtidas pela agremiação na luta contra todas as formas de discriminaçôes motivadas por questôes raciais. Em 5 de setembro de 1936, o jornal relatou que "oficiais brancos" foram expulsos da corporação por simpatizarem com o "ideal e o programa da Frente Negra". Imediatamente, os membros da organização teriam encaminhado um ofício ao governo, solicitando a reintegração dos oficiais. Além disso, o "comitê executivo dessa poderosa organização" aprovou a doação de um "fundo de emergência para esses homens e suas famílias". ${ }^{18} \mathrm{Em} 12$ de setembro, o Chicago Defender divulgou o caso de "quatro brasileiros brancos" que foram "sumariamente demitidos por dar apoio financeiro e suporte moral à organização conhecida como Frente Negra" ${ }^{19}$ Cerca de quinze dias depois, o jornal noticiou que a controvérsia instaurada em torno da demissão de quatro oficiais do governo, sob a alegação de apoio à Frente Negra, parecia ter chegado praticamente ao final, com "o anúncio, por parte do governo, da possibilidade de realocação dos quatro oficiais" ${ }^{20}$ De acordo com o Chicago Defender, o caso só chegou a bom termo devido à intervenção da FNB.

Passados dois meses, o órgão da imprensa afro-americana voltava a sublimar as conquistas da "mais poderosa organização em toda América do Sul". Em sua edição de 21 de novembro de 1936, ele propalava que o "novo liberalismo brasileiro", no que tange aos direitos civis, "é aclamado como um nítido triunfo do valente determinismo da Frente Negra". Afinal, o governo teria instituído 
metas político-econômicas de longo prazo, buscando a "reabilitação das condições econômicas dos negros". Medidas governamentais "especiais", recentemente promulgadas, "aboliram a discriminação contra negros brasileiros no exército, marinha, repartições federais e lugares públicos”. Em virtude da ação da FNB, "grandes firmas bancárias e comerciais estão fazendo ofertas atrativas para aqueles negros que são qualificados através de experiências e treinamentos para executar suas tarefas. No recente baile anual promovido pelos oficiais do alto escalão, e do qual os negros até agora tinham sido excluídos, mais de duas dúzias de negros e suas famílias estavam presentes e misturados livremente com as filhas e esposas de autoridades do exército e da marinha". ${ }^{21}$

Como se percebe, o Chicago Defender cantava e decantava as façanhas da FNB. Conquanto uma pergunta não quer calar: será que o jornal tinha razão quando aventava a ideia de que a agremiação afro-brasileira estava conseguindo acabar com a discriminação contra os negros? A FNB colheu alguns dividendos como grupo de pressão em questôes que envolviam os direitos civis (Taylor, 1978). Conseguiu eliminar a "linha de cor", que vigorava nos rinques de patinação na cidade de São Paulo, impedindo a participação dos negros. Igualmente, colocou na ordem do dia a política racial de ingresso na Guarda Civil. Embora não houvesse nenhuma legislação que proibisse o ingresso dos negros, a discriminação velada continuava alijando os candidatos desse segmento racial. A FNB teria apelado diretamente ao presidente Vargas, que, "após receber uma delegação da liderança da Frente, ordenou à Guarda que alistasse imediatamente duzentos recrutas negros. No decorrer da década de 1930, cerca de 500 afro-brasileiros ingressaram na milícia do Estado" (Andrews, 1998, p. 234). Assim, é mister reconhecer que a FNB cumpriu um papel proativo, dialogando com atores e agências da sociedade civil e do Estado, articulando-se politicamente, empreendendo uma viçosa mobilização racial, na qual travou embates, labutou por direitos e pleiteou a ampliação da cidadania. Tudo isso é verdade e já foi confirmado por várias pesquisas (Mitchell, 1977; Taylor, 1978; Pinto, 1993; Butler, 1998; Domingues, 2005), entretanto não se deve traçar, para não dizer pintar, um quadro romanceado. Definitivamente, a agremiação não conseguiu erradicar as discriminaçōes raciais, quer aquelas incrustadas na sociedade civil, quer nas instituiçỗes públicas.

\section{Como se fosse bumerangue}

O mais pujante hebdomadário da imprensa negra norte-americana, Chicago Defender, veiculou imagens e representações bastante positivadas da FNB. Para além de um espaço de sociabilidade, cultura e lazer, esta foi tratada como a "mais poderosa organização em toda América do Sul”, "a maior união do continente". ${ }^{22}$ Sua força política constituiria o "fiel da balança" nos horizontes da nação e seu agito teria se tornado "tão formidável" que debelou com o "preconceito". ${ }^{23}$ Qualificada de "poderosa”, "famosa”, "extraordinária" e "notável", a FNB seria uma grandiosa paladina da liberdade, a salvadora da democracia brasileira, ${ }^{24}$ a porta voz mais autorizada para traduzir as aspirações dos negros brasileiros. O jornal da imprensa afro-americana procurou exaltar as glórias e vitórias da FNB. Para tanto, assumiu uma linha editorial apologética, superfaturando alguns dados, exagerando em certas informações e sendo hiperbólico nas adjetivações. Mas por que o Chicago Defender assumiu essa linha editorial?

Uma resposta possível está relacionada com a narrativa de que a FNB foi fundada sob os auspícios de Robert S. Abbott. Em vários momentos, o jornal divulgou essa versão dos fatos. ${ }^{25}$ Para não se alongar, basta citar mais um exemplo disso. No dia 2 de novembro de 1935, o jornal publicou a notícia de que seu editor receberia um "valioso tributo" da Frente Negra, "uma extraordinária instituição cívica” do Brasil. "Esta organização, composta exclusivamente por negros brasileiros", contava a reportagem, "em assembleia admitiu abertamente sua dívida para com a corajosa atitude do editor Abbott”, pela inspiração que seus quadros "receberam na luta contra o advento da propaganda perniciosa americana". Segundo a reportagem, o presidente da convenção declarou: "A Frente Negra surgiu pelo exemplo do grande editor norte-americano Robert S. Abbott. Foi ele quem transplantou ao nosso solo a filosofia mili- 
tante de integração nacional de todos os elementos raciais. Foi ele quem trouxe para o nosso continente os amplos princípios de igualdade, justiça e boa vontade mútua". A reportagem enfatizava o "gratificante pronunciamento" dos negros do Brasil um país "irmão" -, que "são compelidos a lutar contra o terrível achaque do preconceito racial, infelizmente imposto sobre eles pela influência de homens e mulheres da raça branca do nosso país", ou seja, dos Estados Unidos. Tal situação "no mínimo nos impressiona", pois evidencia como "não existe limites para as operaçóes da mente humana voltadas para o bem quando há corajosos e honestos intentos". Para finalizar, a reportagem alinhavava palavras laudatórias a Abbott. Se, internamente, o "povo negro americano" era compelido a lutar contra as "presas venenosas" do racismo na vida política, social e econômica, externamente, era "uma fonte de satisfação perceber que ao menos um negro americano pode proporcionar inspiração e apontar o caminho para superar esses males" ${ }^{26}$

Como foi asseverado anteriormente, a informação de que a FNB veio à baila sob a "inspiração" de Abbott não era exata. Antes de o editor-proprietário do Chicago Defender visitar o Brasil, em 1923, os afro-paulistas já agenciavam uma dinâmica rede associativa, formada por jornais, grêmios literários, clubes, salóes de bailes, centros cívicos, associações beneficentes, grupos teatrais e times de futebol (Butler, 1998; Gomes, 2005). Isto significa dizer que, ao ser fundada em 1931, a FNB não nasceu no vazio histórico, nem foi obra de uma ideia plantada por um afro-americano. Ela foi o resultado do acúmulo de experiência associativa dos afro-paulistas. A versão, portanto, de que Abbott foi o mentor da FNB tratou-se de uma invenção, cuja finalidade era, provavelmente, edificar o editor-proprietário do Chicago Defender como o maior herói e visionário das populações afro-diaspóricas nas Américas. Diante dessa invenção, a linha editorial do jornal não pode ser interpretada como desinteressada. $\mathrm{Na}$ medida em que superestimava as "proezas" e "realizaçôes" da FNB, o jornal automaticamente consagrava a figura de seu proprietário. Em outros termos, diante da invenção, a linha editorial laudatória rendia capital simbólico para Abbott.

No entanto, a explicação mais plausível para o não desprezível destaque dado à FNB pelo Chicago Defender está relacionada com o poder de agenciamento, inserção transnacional e repercussão política da organização dos negros brasileiros no circuito afro-atlântico. Não foi por acaso que ela ficou conhecida como a maior organização do gênero na América do Sul. A mobilização racial protagonizada pela FNB alcançou uma dimensão sem precedentes para uma organização afro-brasileira. Suas ações, propostas e iniciativas eram noticiadas e acompanhadas pelos negros da diáspora. No primeiro sábado de agosto de 1937, a cantora afro-americana Marian Anderson visitou a sede da FNB. Ela teria chegado ao "quartel-general da associação" exatamente às $18 \mathrm{~h} 00$. Na sala de recepção, foi saudada por Justiniano Costa - o então presidente da $\mathrm{FNB}$-, que passou a palavra ao professor José Eusébio dos Santos. Falando em nome de todos os associados, "pertencentes à maior união do continente", este ofereceu uma placa como lembrança para a "ilustre" afro-americana e a aclamou pelo "incomparável sucesso no auge da sua carreira artística”. Agradecendo pela placa, esta expressou a satisfação de estar entre o "povo de sua raça" e disse que se esforçaria para voltar a São Paulo, onde sua arte fora "tão bem compreendida". Para encerrar a visita, um número musical e literário, com a declamação de poemas. Antes de sair do "quartel-general" da FNB, "onde foi saudada por uma grande multidão", Anderson teria registrado suas impressões no livro de visitantes. ${ }^{27}$ Segundo o jornal $A$ Voz da Raça, a sede social da agremiação era visitada quase que diariamente por pessoas da capital paulista e de outras cidades do interior e de outros estados. E o seu valor

[...] já se alardeia e repercute lá fora, transpondo mesmo as fronteiras do País. Miss Marian Anderson, a cantora de ébano, de voz inigualável, quando da honrosa visita que fez a F.N.B. levou vários exemplares do órgão "A Voz da Raça”, além de várias fotografias que são o testemunho do valor dessa entidade, e desta gente obreira e altiva nos anseios da elevação. E Miss Marian Anderson, chegando vitoriosa aos seus pagos, após a sua tournée artística, tornou-se lá em Chicago, no populoso bairro de Harlem, a mais entusiástica propa- 
gandista do valor e dos anseios da coletividade frentenegrina. O jornal "Chicago Defender" que temos sobre a mesa, ilustrado com amplas fotografias nossas e com vários amigos de simpatia ao negro brasileiro e especialmente aos frentenegrinos, é um atestado eloquente da amizade e gratidão que a criadora inabalável do "negro espiritual” vota pela F.N.B. ${ }^{28}$

$A$ Voz da Raça não se equivocava. A fama da FNB extrapolou "mesmo as fronteiras do País". Foi possível inclusive encontrar um caso de africano que se correspondeu com a agremiação, sintonizando-se com aquela "cruzada" em prol do soerguimento moral, cultural e social dos "homens de cor". Da cidade de Lourenço Marques, na "África Portuguesa”, Mário Ferreira redigiu uma carta à $\mathrm{FNB}$, para declarar sua satisfação de tomar conhecimento da existência da agremiação afro-brasileira e lhe solicitar material informativo. ${ }^{29} \mathrm{O}$ renome da FNB se espraiou e cruzou o Atlântico. Este movimento faz pensar que, além do sentido de leste a oeste, isto é, da África para as Américas, deve-se ficar atento para o sentido inverso, para as aportaçôes da diáspora na África. $\mathrm{O}$ gesto de Mário Ferreira também é importante porque indica como os negros se comunicavam, numa relação dialógica entre as duas costas. Esses intercâmbios foram, progressivamente, constituindo as dinâmicas estruturas de comunicação bilateral, e mesmo multilateral, ao mesmo tempo em que pavimentaram e articularam uma visão conectada da experiência negra transatlântica.

A organização dos afro-brasileiros tornou-se um paradigma de movimento social bem-sucedido, alimentando esperanças, fermentando anseios e expectativas, influenciando a luta por direitos civis e impulsionando as retóricas e as políticas raciais levadas a cabo por negros de outras partes do mundo. George Andrews assinala que o exemplo da FNB provocou a "criação do Partido Autóctono Negro no Uruguai em 1937”. Com grande entusiasmo, o Partido Autóctono chegou a participar das eleições e fazer campanhas intensivas para seus candidatos (Andrews, 2007, p. 162). Em sua edição de 11 de janeiro de 1936, o Chicago Defender trazia - logo na primeira página - uma ampla matéria, cuja manchete estampada com letras garrafais era bastante sugestiva: "American Race Group takes cue from Brazil; Maps drive to shake off shackles in 1936" [Grupo Racial Americano toma o exemplo do Brasil; Mapeia campanha para livrar-se dos grilhões em 1936]. A matéria falava da plataforma de atuação e dos desafios da recém-criada "North American Fronte Negra" [Frente Negra Norte-Americana]: "Reagindo ao amargo sofrimento que a Raça tem sido forçada a suportar nas mãos de uma preconceituosa e hostil nação", a Frente Negra Norte-Americana "lançou um implacável programa para 1936, determinada a manter a batalha até que a viciosa política de segregação racial da América seja destruída”. ${ }^{30}$ Não foi possível obter maiores detalhes dessa organização, mas só o fato de ela se remeter à sua congênere afro-brasileira já na escolha do nome é algo deveras surpreendente.

Quando o órgão da imprensa afro-americana pautou a luta dos trabalhadores de Porto Rico, reportou-se ao agito protagonizado pelos comunistas e mencionou o espectro da FNB no país do Caribe. Outrora "indiferentes" aos problemas da massa "sofredora", as autoridades locais encontravam-se, a partir daquele instante, adquirindo consciência de que era "sábio" assistir aos trabalhadores e assim "atrasar a inevitável cristalização da massa em uma frente comum”. Debalde, contava a reportagem, pois os "líderes da classe trabalhadora organizaram uma Frente Negra para solidificar seus interesses e reforçar suas demandas". No final, o jornal fazia uma grande revelação: esse "passo" dos subalternos "habitantes da ilha [do Caribe] foi inspirado pelo sucesso que tem obtido a Frente Negra Brasileira". ${ }^{31}$

Mais do que assumirem a agência de seu destino, os frentenegrinos serviram de fonte de orgulho, entusiasmo e estímulo para seus "irmãos de cor" da rede transatlântica e, no caso dos afrodescendentes da América do Sul, da América do Norte e do Caribe, eles foram concebidos como parâmetro em matéria de organização coletiva. Suas ideias, suas campanhas, suas lutas causaram um impacto considerável, despertando o interesse não só das entidades negras, como de algumas organizações populares sensíveis às lides dos trabalhadores. Apesar das dificuldades de se obter notícias externas e da precariedade da imprensa na década de 1930, os africanos e seus descendentes em diáspora não vi- 
viam isolados uns dos outros; pelo contrário, eles interagiam num circuito vivo e dinâmico de trocas de experiências, de circulação de ideias e de conexões político-culturais. Nesse circuito, os afro-brasileiros não cumpriram um papel de passividade diante das influências externas, quer aquelas advindas dos Estados Unidos, quer aquelas do Caribe ou mesmo da África.

No dia 7 de março de 1936, o Chicago Defender publicou uma reportagem na qual discutia um controvertido projeto de colonização da África pelos negros nascidos na "América". Apresentado na Assembleia Legislativa do Estado norte-americano da Virgínia, o projeto teve apoio de todos aqueles que defendiam a "repatriação do povo afrodescendente para Libéria como um meio de resolver o problema racial". Todavia, líderes da "raça" e organizações negras, preocupados com essa "bomba" que ameaçava causar graves danos a todo "progresso que a raça conseguiu nesse país desde a emancipação", condenaram o projeto: "Nosso lugar e lar são os Estados Unidos, onde nascemos e onde, segundo a constituição, somos cidadãos”. Inconformado, um líder negro de Chicago argumentou a partir do exemplo brasileiro:

No Brasil, a apenas dois dias da África, os negros não estão partindo para o continente africano. Em vez disso, eles estão resolvendo suas próprias questôes no Brasil. Eles têm a Frente Negra, uma organização de negros e brancos que concentra todos os esforços no Brasil para fazer com que todos, independentemente de cor ou raça, tenham chances iguais. ${ }^{32}$

Mesmo cientes dos dilemas, desafios e impasses de seus "irmãos de cor" de outras partes do mundo, os afro-brasileiros fizeram escolhas e abraçaram um projeto emancipatório próprio, baseado no binômio "raça" e "nação". Em vez de um projeto separatista, caracterizado pela formação de instituições paralelas, ou mesmo pelo retorno à África, preconizava-se a assimilação à comunidade nacional. Para os quadros da FNB, a luta contra o "preconceito de cor" era uma luta nacional, ainda que com implicações locais ou globais. ${ }^{33} \mathrm{O}$ mais interessante, porém, dessa reportagem do Chicago Defender é cons- tatar que, para solucionar o problema dos negros nos Estados Unidos, o projeto racial da FNB foi discutido, comparado e ventilado como alternativa por um líder afro-americano. Isto mostra como, no circuito afro-atlântico, os percursos são cruzados. No lugar de enfeixados em uma via de mão única, os signos e referentes das lutas políticas, estratégias de militância e narrativas de igualdade racial circulavam dinamicamente e viajavam nas redes de conexões político-culturais.

A FNB manteve intercâmbios dentro e afora dos limites do território nacional e, por vezes, espelhou-se seletivamente na experiência histórica dos afro-americanos. Em determinada edição, o jornal Chicago Defender publicou a carta de um membro da diretoria da agremiação afro-brasileira, congratulando-se com Robert Abbott e o convidando para participar do Congresso Universal da Raça, previsto para ocorrer em São Paulo no dia 23 de maio de $1938 .{ }^{34}$ Não obstante, a recíproca era verdadeira. A FNB tornou-se uma referência para alguns ativistas afro-americanos. Sua sede foi visitada por símbolos da modernidade afro-diaspórica, como a cantora Marian Anderson, e notícias sobre a organização foram divulgadas no "meio negro" dos Estados Unidos. Nesse movimento circular, de permutas de ideias, experiências e cosmovisões, os afro-brasileiros surpreenderam os afro-americanos não somente no terreno político, como em outras esferas da vida social e estético-cultural. Uma dessas situaçōes foi documentada pelo Chicago Defender. Em sua edição de 9 de março de 1940, o jornal revelava que Robert Abbott foi o responsável pela introdução, no meio negro dos Estados Unidos, do "talentoso poeta lírico do Brasil Cruz e Souza, cujos poemas são respeitados por autoridades competentes como uma das mais representativas joias literárias do Brasil". ${ }^{35}$

Portanto, a explicação mais convincente para o relativo destaque conferido à FNB pelo Chicago Defender diz respeito ao prestígio que esta organização auferiu no circuito afro-atlântico. $\mathrm{O}$ bradar dos negros no Brasil ecoou e chegou aos ouvidos de seus "irmãos de cor" do outro lado da linha do Equador. Até lá, o oceano Atlântico, com o ritmo de suas ondas, seus ventos e suas marés, levou e transmitiu ideias de raça, identidade, cul- 
tura e nação. Quando aportadas, essas ideias foram apropriadas e ressignificadas em contextos locais. É verdade que, nas primeiras décadas do século XX, as "garras" da hegemonia cultural norte-americana começavam a se insinuar sobre o Brasil; com efeito não é menos verdade que, em matéria de política racial, os ventos daqui igualmente sopravam sobre lá. Ciente da importância da FNB no cenário do transnacionalismo negro, Abbott não perdeu a oportunidade de abrir espaço em seu jornal para acompanhar a trajetória da agremiação afro-brasileira. E como esta era vista como um ícone de luta e resistência no circuito afro-atlântico, nada mais "natural" do que carregar na tinta para retratá-la, transmitindo imagens e representaçōes panegíricas, celebrativas e triunfalistas.

Em obra seminal, Paul Gilroy advertiu para a importância de apreender as experiências e vivências das populações afro-diaspóricas inseridas no sistema Atlântico Negro, esse versátil sistema formado pelos fluxos e refluxos contínuos de pessoas, informações, símbolos e artefatos político-culturais. Entretanto, o sociólogo inglês concentra sua atenção no hemisfério Norte - sobretudo no mundo de língua inglesa, europeu e americano - e pouco investiga a contribuição dos afro-brasileiros para o fazer-se dessa rede de conexões e transferências. ${ }^{36}$ Urge aprofundar essa questão, (re)dimensionando a participação do "Atlântico Negro Sul" no processo de formulação de estéticas, ideias e expectativas que viajaram por diversos rincões, sendo apropriadas e recombinadas no Novo Mundo, na Europa e na África.

Embora vivas e pulsantes, as conexões afro-diaspóricas na arena transnacional não anulam a alteridade. Afinal de contas, elas são mediadas pela dinâmica de "leitura" e "tradução": os afrodescendentes interpretam as mensagens externas em termos locais, ressignificando-as ou adaptando-as a partir de suas próprias categorias culturais e seus programas políticos (French, 2002, p. 121; Fry, 2005 , p. 210). A pesquisadora Micol Seigel mostra bem isso ao esquadrinhar o movimento que reivindicava a construção do monumento à "mãe preta”, em 1926. Lançado pelo jornalista Cândido de Campos, redator do diário carioca A Notícia, o movimento recebeu o apoio de diferentes segmentos da sociedade - como jornalistas, políticos, religio- sos, estudantes, militantes e artistas -, tanto negros quanto brancos, do Brasil e do exterior. As leituras do jogo, porém, divergiam. Enquanto os militantes afro-brasileiros aproveitaram o movimento como vitrine para dar visibilidade às retóricas de igualdade racial e inscrever as expectativas de cidadania na agenda nacional, o jornal de Abbott preferiu interpretar o movimento no sentido de reforçar a visão de que as relações raciais no Brasil eram opostas às dos Estados Unidos. Em vez de conflito e de segregação entre pessoas negras e brancas, aqui prevaleceria o clima de confraternização racial e união nacional. Por isso, em sua cobertura do movimento pró-monumento à mãe preta, o Chicago Defender "zelosamente se recusou a chamar os afro-brasileiros de 'negros', ou do termo menos usual black (preto), ou caracterizar o movimento como associado a uma raça em particular" (Seigel, 2007, p. 334).

Retomando então a polêmica desencadeada por Pierre Bourdieu e Loïc Wacquant (2002). O movimento negro brasileiro tem sido acusado de ser mero receptor e reprodutor passivo, mimetizando políticas, modismos e retóricas raciais forjadas e orquestradas pelos Estados Unidos. Será que as trocas intelectuais fluem apenas em uma direção - como argumentaram os sociólogos franceses? Será que o movimento negro brasileiro nunca influenciou o seu congênere nos Estados Unidos? Centrado no período anterior à Segunda Guerra Mundial e ao Movimento dos Direitos Civis, este artigo apresentou evidências que demandam uma resposta menos simplificada e dicotômica, posto que o movimento negro local também foi produtor e irradiador de ideias, políticas e narrativas, as quais ultrapassaram a fronteira nacional e tiveram ressonância em solo yankee. Ademais, como pesquisas recentes vêm sugerindo (Seigel, 2009), a questão parece ser menos de "origem" e/ou de "influência” de ideias e mais da circulação, da apropriação e dos significados em torno delas.

A diáspora africana é um processo que, embora em permanente formação (Kelley e Patterson, 2000), legou o desenvolvimento de um conjunto de "comunidades imaginadas" (Hanchard, 1999; Butler, 2001). Partindo de uma abordagem transatlântica, cabe ao pesquisador perscrutar no interior da diáspora as fontes de diálogos e interligações, os 
percursos cruzados e entrecruzados, os pontos de aproximação, afastamento e intersecção; em suma, cabe ao pesquisador mirar nos "contextos transnacionais de ação" (Costa, 2006, pp. 124-126). Como se fossem um bumerangue, informações, articulações, projetos ideológicos, sonhos, fé e esperança de ativistas e organizaçôes afro-diaspóricas transitavam, e mesmo giravam, com idas e voltas, em movimentos multilaterais em vias de mão dupla. As conexóes estabelecidas entre o Chicago Defender e a FNB desvendam uma teia de interesses compartilhados, mas também são barômetros de interpretações peculiares sobre a política racial nos umbrais do Atlântico Negro.

Duas últimas palavras. Numa perspectiva mais ampla, este artigo acenou para o respeito e a admiração mútua que os negros dos Estados Unidos e do Brasil mantinham entre si. Mais ainda. Apontou algumas pistas acerca das reverberações da diáspora deste país naquele, assunto ainda pouco explorado pelos pesquisadores. $\mathrm{O}$ foco apenas no lado norte-americano minimiza (ou oblitera) importantes aspectos históricos do lado brasileiro (Pinho, 2005), como, por exemplo, as formas de luta e resistência dos afro-descendentes no pós-abolição, e o papel que estes desempenharam na rede de comunicação transatlântica, contribuindo, assim, para a elaboração e reelaboração dos referentes político-culturais contemporâneos.

\section{Notas}

1 "Intellect is the only road to freedom, says editor R. S. Abbott". Chicago Defender, 8 dez. 1934, p.11. Todas as traduções deste artigo são de minha responsabilidade.

2 A metáfora do bumerangue foi pioneiramente adotada por Peter Linebaugh para designar a comunicação, a circulação de ideias e as trocas de experiências dos trabalhadores dos quatro cantos do Atlântico - América do Norte e do Sul, Europa e África, por meio da navegação comercial ultramarina. Seu argumento é de que a formação da classe trabalhadora inglesa alimentou e, reciprocamente, foi alimentada pelas experiências históricas e tradiçôes de luta e rebeldia dos negros, fossem escravizados ou livres (Linebaugh, 1993). Posteriormente, em conjunto com Marcus Rediker, Linebaugh retomou e aprofundou o argu- mento de que os contatos e as cooperaçóes existentes entre os diferentes grupos subalternos - plebeus sem posses, trabalhadores urbanos, soldados, marinheiros, africanos escravizados - constituíram elementos importantes no processo de formação de uma classe trabalhadora atlântica (Linebaugh e Rediker, 2008). No Brasil, a metáfora do bumerangue foi utilizada por Flávio dos Santos Gomes para apreender a movimentação, as interseccionalidades e relações dialógicas dos quilombolas e dos fugitivos escravos nos limites territoriais da Amazônia colonial (Gomes, 1995-1996).

3 A Voz da Raça. São Paulo, set. 1936, p. 1.

4 Sobre a Frente Negra Baiana, Pelotense e Pernambucana, ver, respectivamente, Beatriz Ana Loner (1999, pp. 400-428), Jeferson Bacelar (1996, pp. 73-85) e Maria Auxiliadora Gonçalves da Silva (1994, pp. 5859).

5 "Organize society to fight U. S. color bans in Brazil". Chicago Defender, 14 out. 1933, p. 1.

6 "Brazilians in tribute for publisher". Chicago Defender, 26 out. 1935, p. 1.

7 "Brazilians invite editor to address race congress". Chicago Defender, 6 nov. 1937, p. 6. Ver também "Whites in Brazil ask members of Fronte Negra for admittance". Chicago Defender, 25 jan. 1936, p. 24.

8 Eis como Helio Lobo - um diplomata que se tornou cônsul-geral do Brasil em Nova York - referiu-se à "imprensa de cor” nos Estados Unidos, em 1923: "para sua multiplicação e eficiência crescente, [a imprensa de cor tem] como motivos fundamentais estes: primeiro, ser o órgão por onde a raça deve falar ao país; segundo, procurar destruir na opinião os mal-entendidos que, a seu ver, criam frequentemente os cabeçalhos e editoriais da imprensa branca. Em oposição à White Star Line, criaram os pretos da América a Black Star Line, destinada a estabelecer comunicações marítimas com a África. À semelhança da Associated Press, instituíram também a Associated Negro Press. É o mesmo princípio fundamental da divulgação e troca de notícias, mas a reivindicação dos chamados direitos sacrificados está em tudo que respeita à segunda. Se nas regiōes da terra, onde existem pretos, já há 17 jornais, só nos Estados Unidos da América há 220. Além desses jornais, dois dos quais são diários, contam-se aqui 70 publicações de índole religiosa, 85 de forma escolar, 37 gerais" (Lobo, 1923, p. 68). Sobre a imprensa negra nos Estados Unidos, existem vários estudos. Para um autor clássico, ver Edward Franklin Frazier ([1957] 1997); já para abordagens mais contemporâneas, ver Armistead Scott Pride e Clint C. Wilson II (1997). 
9 Theodore Kornweibel Jr. (1994, p. 157) estima que o número de leitores do Chicago Defender chegou a um milhão por semana até o final da Primeira Guerra Mundial (1914-1919). Talvez sua estimativa seja exagerada, mas serve de indicador da projeção do jornal da imprensa negra de maior circulação nos Estados Unidos no período.

10 Em livro de memórias, José Correia Leite, o fundador e editor d'O Clarim da Alvorada, em São Paulo, revela como se deu a aproximação com o Chicago Defender. Havia um colaborador no Rio de Janeiro, Olímpio de Castro, um padre negro, que conheceu Abbott por ocasião de sua visita ao Brasil. Naquela época estava em curso o movimento para se erigir o monumento em homenagem à "Mãe Negra", o que despertou o interesse do editor do Chicago Defender. Depois de ter passado algum tempo de seu retorno aos Estados Unidos, Abbott escreveu para Olímpio de Castro, perguntando como andava a movimentação em torno da proposta do monumento à "Mãe Negra". Este então procurou $O$ Clarim da Alvorada, explicando que, lá no Rio de Janeiro, estava desatualizado sobre o assunto. Como o jornal dos afro-paulistas acabara de publicar um número sobre o monumento à "Mãe Negra", seus editores o enviaram a Olímpio de Castro que, por sua vez, remeteu para os Estados Unidos. "Dali nós começamos a receber o Chicago Defender", afirma José Correia Leite. "Foi o primeiro contato que nós tivemos com o negro norte-americano. E houve depois uma permuta. A gente também mandava $O$ Clarim d'Alvorada pra lá" (Leite, 1992, pp. 78-79).

11 "Editor Abbott an inspiration abroad". Chicago Defender, 9 mar. 1940, p. 8.

12 "Brazilian race congress stands firm for solidarity". Chicago Defender, 9 nov. 1935, p. 24.

13 "Fronte Negra seeks financial security". Chicago Defender. 13 jun. 1936, p. 24.

14 "Frente Negro may be O. K.'d in Brazil". Chicago Defender, 14 mar. 1936, p. 24.

15 "Fronte Negra of Brazil in stern fight". Chicago Defender. 8 fev. 1936, p. 24.

16 "Brazil presidency depends on parley". Chicago Defender, 5 dez. 1936, p. 24.

17 "Brazilian politics seeking support of the "Black Front". Chicago Defender, 20 mar. 1937, p. 24. Em reportagem do final daquele ano, o periódico afro-americano dizia que "a Frente Negra Brasileira, uma organização muito militante", reunia "200.000 membros", o que é um grande exagero. "Brazilians oppose fascist dictator". Chicago Defender, 11 dez. 1937, p. 24.
18 "Brazilian officials ousted for interest in race movement". Chicago Defender, 5 set. 1936, p. 24.

19 "Dixie prejudice invades Brazil; officers are ousted for aiding Fronte Negra”. Chicago Defender, 12 set. 1936, p. 1.

20 "Ousted brazilians to be reinstated". Chicago Defender, 26 set. 1936, p. 24

21 "Brazil's new liberalism is hailed as a truimph". Chicago Defender, 21 nov. 1936, p. 24.

22 "Brazil lauds Marian Anderson". Chicago Defender, 7 ago. 1937, p. 24.

23 "Intellect is the only road to freedom, says editor R. S. Abbott". Chicago Defender, 8 dez. 1934, p. 11.

24 O Chicago Defender também se esforçou para associar a imagem da FNB à defesa da democracia. Na edição de 11 de dezembro de 1937, o periódico alardeava que os ditadores fascistas europeus - Mussolini e Hitler - "solicitam que Vargas expurgue do exército e do serviço civil todos os oficiais de cor". Tratava-se, pois, do primeiro passo da "campanha" em prol da "pureza da raça". Mesmo com Vargas assumindo "poderes ditatoriais absolutos", tal medida, dizia o jornal, encontrará "formidável oposição da população de cor", principalmente nos "estados da Bahia e Pernambuco". Cerca de "dez milhōes de bravos" negros brasileiros estavam contrários à ditadura fascista, razão pela qual "qualquer substituição do negro pelo branco no exército ou na administração pública" levará a uma "revolta contra a ditadura". $\mathrm{Na}$ defesa da democracia e dos direitos econômicos, políticos e sociais da "população de cor", entrava em cena a FNB, de modo que esta agremiação, "com mais de 200.000 membros", já tinha comunicado ao "presidente Vargas que ela irá se opor à qualquer medida que implique restringir os direitos da população". Segundo o Chicago Defender, a FNB instava pelos direitos individuais, pelas prerrogativas constitucionais e pelas liberdades democráticas, o que implicava, evidentemente, rebelar-se contra a escalada do autoritarismo no país. "Brazilians oppose fascist dictator". Chicago Defender, 11 dez. 1937, p. 24.

25 "Organize society to fight U. S. color bans in Brazil". Chicago Defender, 14 out. 1933, p. 1; "Brazilians in tribute for Publisher". Chicago Defender, 26 out. 1935, p. 1; "Catching the Abbott spirit". Chicago Defender, 2 nov. 1935, p. 16; "Brazilians invite editor to address race congress". Chicago Defender, 6 nov. 1937, p. 6; "Editor Abbott an inspiration abroad". Chicago Defender, 9 mar. 1940, p. 8.

26 "Catching the Abbott spirit". Chicago Defender, 2 nov. 1935 , p. 16. 
27 "Brazil lauds Marian Anderson". Chicago Defender, 7 ago. 1937, p. 24. Sobre a visita da Marian Anderson à FNB, ver também "Brazilians send congratulations" e "Noted american Race Singer is big sensation". Chicago Defender, 7 ago. 1937, p. 24.

28 "Comentando". A Voz da Raça. São Paulo, nov. 1937, p. 4.

29 "De Além-mar". A Voz da Raça. São Paulo, 18 mar. 1933, p. 4.

30 "American Race Group takes cue from Brazil; Maps drive to shake off shackles in 1936". Chicago Defender, 11 jan. 1936, p. 1.

31 "Puerto Ricans organize black militante front". Chicago Defender, 11 jan. 1936, p. 24.

32 "Nation stirred over move to colonize race in Africa". Chicago Defender, 7 mar. 1936, p. 1.

33 A esse respeito, o depoimento de Francisco Lucrécio é emblemático: "Na Frente Negra não tinha essa discussão de volta à África. Tínhamos correspondência com Angola, conhecíamos o movimento de Marcus Garvey [um importante líder afro-jamaicano que, nos Estados Unidos, chegou a preconizar o retorno de todos os negros à África], mas não concordávamos. Nós sempre nos afirmamos como brasileiros e assim nos posicionávamos [...]. Não queríamos perder nossa identidade de brasileiros" (Lucrécio et al., 1998, p. 46).

34 "Brazilians invite editor to address race congress". Chicago Defender, 6 nov. 1937, p. 6.

35 "Editor Abbott an inspiration abroad". Chicago Defender, 9 mar. 1940, p. 8.

36 O próprio Gilroy denuncia, no prefácio à edição brasileira de seu livro, "o quanto a história brasileira tem sido marginalizada mesmo nos melhores relatos sobre a política negra centrados na América do Norte e no Caribe" (Gilroy, 2001, p. 11). A despeito da denúncia, seu livro não sinaliza para a mudança desse quadro, na medida em que reserva apenas duas ou três superficiais referências ao Brasil.

\section{BIBLIOGRAFIA}

ANDREWS, George Reid. (1998), Negros e brancos em São Paulo (1888-1988). Bauru, SP, Edusc. . (2007), América Afro-Latina (18002000). São Carlos, SP, EdUFSCar.

BACELAR, Jeferson. (1996), “A Frente Negra Bra- sileira na Bahia”. Afro-Asia (17): 73-85.

BOURDIEU, Pierre \& WACQUANT, Loïc. (2002), "Sobre as artimanhas da razão imperialista". Estudos Afro-Asiáticos, 24 (1): 15-33.

BUTLER, Kim D. (1998), Freedoms given, freedoms won: afro-brazilians in post-abolition São Paulo and Salvador. New Brunswick, NJ, Rutgers University Press.

(2001), "Defining diaspora, refining a discourse". Diaspora: a Journal of Transnational Studies, 10 (2): 189-219.

COSTA, Sérgio. (2006), Dois Atlânticos: teoria social, anti-racismo, cosmopolitismo. Belo Horizonte, Editora UFMG.

DOMINGUES, Petrônio José. (2005), A insurgência de ébano: a história da Frente Negra Brasileira. São Paulo, tese de doutorado em História, Universidade de São Paulo.

FERNANDES, Florestan. (1978), A integração do negro na sociedade de classes. São Paulo, Ática, 2 vols.

FRY, Peter. (2005), "Política, nacionalidade e o significado de 'raça' no Brasil", in Ensaios antropológicos sobre o Brasil e a África austral, Rio de Janeiro, Civilização.

FRAZIER, Franklin E. ([1957] 1997), "The negro press and wish-fulfillment", in Black bourgeoisie. Nova York, Free Press.

FRENCH, John. (2002), "Passos em falso da razão antiimperialista: Bourdieu, Wacquant, e o Orfeu e o Poder de Hanchard". Estudos Afro-Asiáticos, 24 (1): 97-140.

GILROY, Paul. (2001), O Atlântico negro: modernidade e dupla consciência. São Paulo, Editora 34. (2007). Entre campos: naçôes, cultura e o fascinio da raça. São Paulo, Annablume.

GOMES, Flávio dos Santos. (1995-1996), "Em torno dos bumerangues: outras histórias de mocambos na Amazônia colonial”. Revista USP, (28): 41-55. . (2005), Negros e política (1888-1937). Rio de Janeiro, Jorge Zahar.

HALL, Stuart. (2003), Da diáspora: identidades e mediaçôes culturais. Belo Horizonte/Brasília, Editora UFMG/Representação da Unesco no Brasil.

HANCHARD, Michael. (1999), "Afro-modernity: 
temporality, politics, and the African diaspora”. Public Culture, 11 (1): 245-268. . (2001), Orfeu e o poder: movimento negro no Rio de Janeiro e São Paulo (1945-1988). Rio de Janeiro, Eduerj. . (2002), "Política transnacional negra, antiimperialismo e etnocentrismo para Pierre Bourdieu e Loïc Wacquant: exemplos de interpretação equivocada". Estudos Afro-Asiáticos, 24 (1): 63-96.

HELLWIG, David. (1988), "A new frontier in a racial paradise: Robert S. Abbott's Brazilian dream”. Luso-Brazilian Review, 25 (1): 59-67.

KELLEY, Robin D. G. (1999), "'But a local phase of a world problem': black history's global vision, 1883-1950". The Journal of American History, 86 (3), 1045-1077.

KELLEY, Robin D. G. \& PATTERSON, Tiffany Ruby. (2000), "Unfinished migrations: reflections on the African diaspora and the making of the modern world". African Studies Review, 43 (1): 11-45.

KORNWEIBEL, Theodore, Jr. (1994), “The most dangerous of all negro journals's: federal efforts to suppress the Chicago Defender during World War I". American Journalism, 11 (2): 154-168.

LEITE, José Correia. (1992), ...E disse o velho militante José Correia Leite: depoimentos e artigos. Organização e textos de Luiz Silva Cuti. São Paulo, Secretaria Municipal de Cultura.

LINEBAUGH, Peter. (1983), "Todas as montanhas atlânticas estremeceram". Revista Brasileira de História, (6): 7-46.

LINEBAUGH, Peter \& REDIKER, Marcus. (2008), A hidra de muitas cabeças: marinheiros, escravos, plebeus e a história oculta do Atlântico revolucionário. São Paulo, Companhia das Letras.

LOBO, Helio. (1923), Cousas americanas e brasileiras. Rio de Janeiro, Imprensa Nacional, vol. 1.

LONER, Beatriz Ana. (1999), Classe operária: mobilização e organização em Pelotas (18881937). Porto Alegre, tese de doutorado em Sociologia, Universidade Federal do Rio Grande do Sul, vol. 2.

LUCRÉCIO, Francisco et al. (1998), Frente Negra Brasileira: depoimentos. Entrevistas e textos: Márcio Barbosa. São Paulo, Quilombhoje.
MARX, Anthony W. (1996), "A construção da raça e o Estado-nação". Estudos Afro-Asiáticos, (29): 9-36.

MYRDAL, Gunnar. (1944), An American dilemma: the negro problem and moderny democracy. Nova York, Harper \& Row.

MITCHELL, Michael. (1977), Racial consciousness and the political attitudes and behavior of blacks in São Paulo, Brazil. Bloomington, PhD em Ciência Política, Indiana University.

OTTLEY, Roi. (1955), The lonely warrior: the life and times of Robert S. Abbott. Chicago, Henry Regnety.

PINHO, Patrícia de Santana. (2005), "Descentrando os Estados Unidos nos estudos sobre negritude no Brasil". Revista Brasileira de Ciências Sociais, 20 (59): 37-50.

PINTO, Regina Pahim. (1993), O movimento negro em São Paulo: luta e identidade. São Paulo, tese de doutorado em Ciências Sociais, Universidade de São Paulo.

PRIDE, Armistead Scott \& WILSON II, Clint C. (1997), A history of the black press. Washington, Howard University Press.

SANSONE, Lívio. (2002), "Um campo saturado de tensões: o estudo das relações raciais e das culturas negras no Brasil”. Estudos Afro-Asiáti$\cos , 24$ (1): 5-14.

SEIGEL, Micol. (2007), "Mães pretas, filhos cidadãos", in Flávio dos Santos Gomes e Olívia Maria Gomes da Cunha (orgs.), Quase-cidadão: histórias e antropologias da pós-emancipação no Brasil, Rio de Janeiro, FGV. . (2009), Uneven encounters: making race and nation in Brazil and The United States. Durham, NC, Duke University Press.

SILVA, Maria Auxiliadora Gonçalves da. (1994), Encontros e desencontros de um movimento negro. Brasília, Fundação Cultural Palmares.

TAYLOR, Quintard. (1978), "Frente Negra Brasileira: the afro-brazilian civil rights movement, 1924-1937". Umoja: A Scholarly Journal of Black Studies, 2 (1): 25-40.

TELLES, Edward. (2002), "As fundações norte-americanas e o debate racial no Brasil”. Estudos Afro-Asiáticos, 24 (1): 141-165. 


\section{COMO SE FOSSE BUMERANGUE: FRENTE NEGRA BRASILEIRA NO CIRCUITO TRANSATLÂNTICO}

\section{Petrônio Domingues}

Palavras-chave: Diáspora africana; Diálogos atlânticos; Raça; Afro-americano; Negro.

A finalidade deste artigo é examinar como a Frente Negra Brasileira - a mais notável organização dos afro-brasileiros nas primeiras décadas do regime republicano -, foi retratada pelo Chicago Defender, o jornal de maior circulação da imprensa negra nos Estados Unidos. A ideia central é mostrar que o Chicago Defender produziu um discurso celebrativo da Frente Negra, com direito a inflar dados e informações e incorrer em exageros laudatórios. Este discurso, apesar de problemático e paradoxal, é importante porque permite vislumbrar as interlocuções, interdependências e conexões estabelecidas pelos negros dos dois lados da linha do Equador e, ao mesmo tempo, redimensionar o papel do Brasil no circuito afro-atlântico.

\section{LIKE A BOOMERANG: THE FRENTE NEGRA BRASILEIRA IN THE TRANSATLANTIC CIRCUIT}

\section{Petrônio Domingues}

Keywords: African diaspora; Atlantic dialogues; Race; African-American; Black.

The aim of this article is to examine how the FNB (the Black Brazilian Front) - the most notable Afro-Brazilian organization of the first decades of the republican regime - was depicted in the Chicago Defender, the Black newspaper with wider circulation in the USA. The central concern is to show that the Chicago Defender produced a celebrative discourse about the Frente Negra Brasileira, inflating statistics and information, and engaging in laudatory exaggerations. In spite of its problematic and paradoxical character, such discourse is important because it reveals the interlocutions, interdependencies, and connections established by Blacks on both hemispheres and, at the same time, allows a reconfiguration of the role of Brazil in the AfroAtlantic circuit.

\section{COMME SI C'ÉTAIT UN BOOMERANG: FRONT NOIR BRÉSILIEN DANS LE CIRCUIT TRANSATLANTIQUE}

\section{Petrônio Domingues}

Mos-clés: Diaspora africaine; Dialogues atlantiques; Race; Afro-américain; Noir.

Le but de cet article est d'examiner de quelle façon le Front Noir - la plus notable organisation d'afro-brésiliens dans les premières décennies du régime républicain - a été retracée par le Chicago Defender, le journal de plus grande circulation de la presse noire aux États-Unis. Lidée centrale est de démontrer que le Chicago Defender a produit un discours qui célèbre le Front Noir, en y incluant le droit à grossir les données et les informations et encourir en des louanges exagérées. Ce discours, malgré le fait d'être problématique et paradoxal, est important car il permet d'entrevoir les interlocutions, les interdépendances et les connexions établies par les noirs des deux côtés de la ligne de l'Équateur et, en même temps, de redimensionner le rôle du Brésil dans le circuit afro-atlantique. 